\title{
Aspergillus niger as a Secondary Metabolite Factory
}

\author{
Ronglu Yu ${ }^{1}$, Jia Liu ${ }^{1}$, Yi Wang ${ }^{1}$, Hong Wang ${ }^{1,2}$ and Huawei Zhang ${ }^{1,2 *}$ \\ ${ }^{1}$ School of Pharmaceutical Sciences, Zhejiang University of Technology, Hangzhou, China, ${ }^{2}$ Key Laboratory of Marine Fishery \\ Resources Exploitment and Utilization of Zhejiang Province, Hangzhou, China
}

Aspergillus niger, one of the most common and important fungal species, is ubiquitous in various environments. A. niger isolates possess a large number of cryptic biosynthetic gene clusters (BGCs) and produce various biomolecules as secondary metabolites with a broad spectrum of application fields covering agriculture, food, and pharmaceutical industry. By extensive literature search, this review with a comprehensive summary on biological and chemical aspects of $A$. niger strains including their sources, BGCs, and secondary metabolites as well as biological properties and biosynthetic pathways is presented. Future perspectives on the discovery of more $A$. niger-derived functional biomolecules are also provided in this review.

Keywords: Aspergillus niger, secondary metabolite, bioactivity, biosynthesis, application

\section{OPEN ACCESS}

Edited by:

Yuanyuan Lu,

China Pharmaceutical University,

China

Reviewed by:

Weaam Ebrahim,

Mansoura University, Egypt

Paul-Henri Ducrot,

INRA UMR1318 Institut Jean Pierre

Bourgin, France

*Correspondence:

Huawei Zhang

hwzhang@zjut.edu.cn

Specialty section: This article was submitted to

Organic Chemistry, a section of the journal

Frontiers in Chemistry

Received: 30 April 2021

Accepted: 28 May 2021

Published: 30 July 2021

Citation:

Yu R, Liu J, Wang Y, Wang $H$ and Zhang $H$ (2021) Aspergillus niger as a Secondary Metabolite Factory.

Front. Chem. 9:701022.

doi: 10.3389/fchem.2021.701022

\section{INTRODUCTION}

Aspergillus, one sizeable genus belonging to Aspergillaceae family, comprises as many as 492 species registered on the database of the National Center for Biotechnology Information (NCBI) to date. Its section Nigri is an important group of species, and the A. niger aggregate represents its most complicated taxonomic subgroup with eight morphologically indistinguishable taxa (Perrone et al., 2011). Owing to superior adaptability and survivability, A. niger is ubiquitous in nature, including in terrestrial soil (Xie et al., 2006), ocean (Li et al., 2016; Uchoa et al., 2017), the Arctic (Singh et al., 2011), and space. It also occupies a wide spectrum of habitats in plants and animals such as herb (Shreelalitha and Sridhar, 2015; Manganyi et al., 2018), shrub (Kaur et al., 2015; Liu et al., 2016), tree (Soltani and Moghaddam, 2014; Wang et al., 2019), lichen (Elissawy et al., 2019), shrimp (Liu et al., 2013; Fang et al., 2016), and marine sponge (Takano et al., 2001; Hiort et al., 2004). A. niger strain grows well in various media with different carbon sources, including glucose, bran, maltose, xylan, xylose, sorbitol, and lactose (Toghueo et al., 2018). However, its metabolism is remarkably affected by culture conditions, such as medium composition and fermentation mode.

The genome features of strain L14 are summarized in a polycyclic graph (Figure 1), which consists of in-paralog pair, GC skew, widely, SM biosynthetic gene cluster (BGC), ncRNA, repeat, strand coding sequence (CDS) annotation, and scaffold. There are some in-paralog pairs between different scaffolds, and SM BGCs and CDS distributed widely in genome. As shown in Table 1, genome sizes of WT A. niger strains range from 33.8 to $36.1 \mathrm{Mb}$. Their $\mathrm{G}+\mathrm{C} \%$ and gene numbers are closely similar, while the numbers of scaffolds are different owing to various sequencing and assembling manners. The antibiotics and Secondary Metabolite Analysis Shell (antiSMASH) results indicated that each WT A. niger strain harbors at least 20 cryptic SM BGCs, including PKS, NRPS, NRPS-like, and their hybrids (Figure 2 and Supplementary Table S1) (Blin et al., 2019). These BGCs involving in indole and terpene biosynthesis are ubiquitous and have great potential to synthesize therapeutical agents and pesticides, such as AbT1, azanigerone A, fusarin, ferrichrome, nidulanin A, melanin, TAN-1612, yanuthone D, and aflavarin (Supplementary Table S2). 


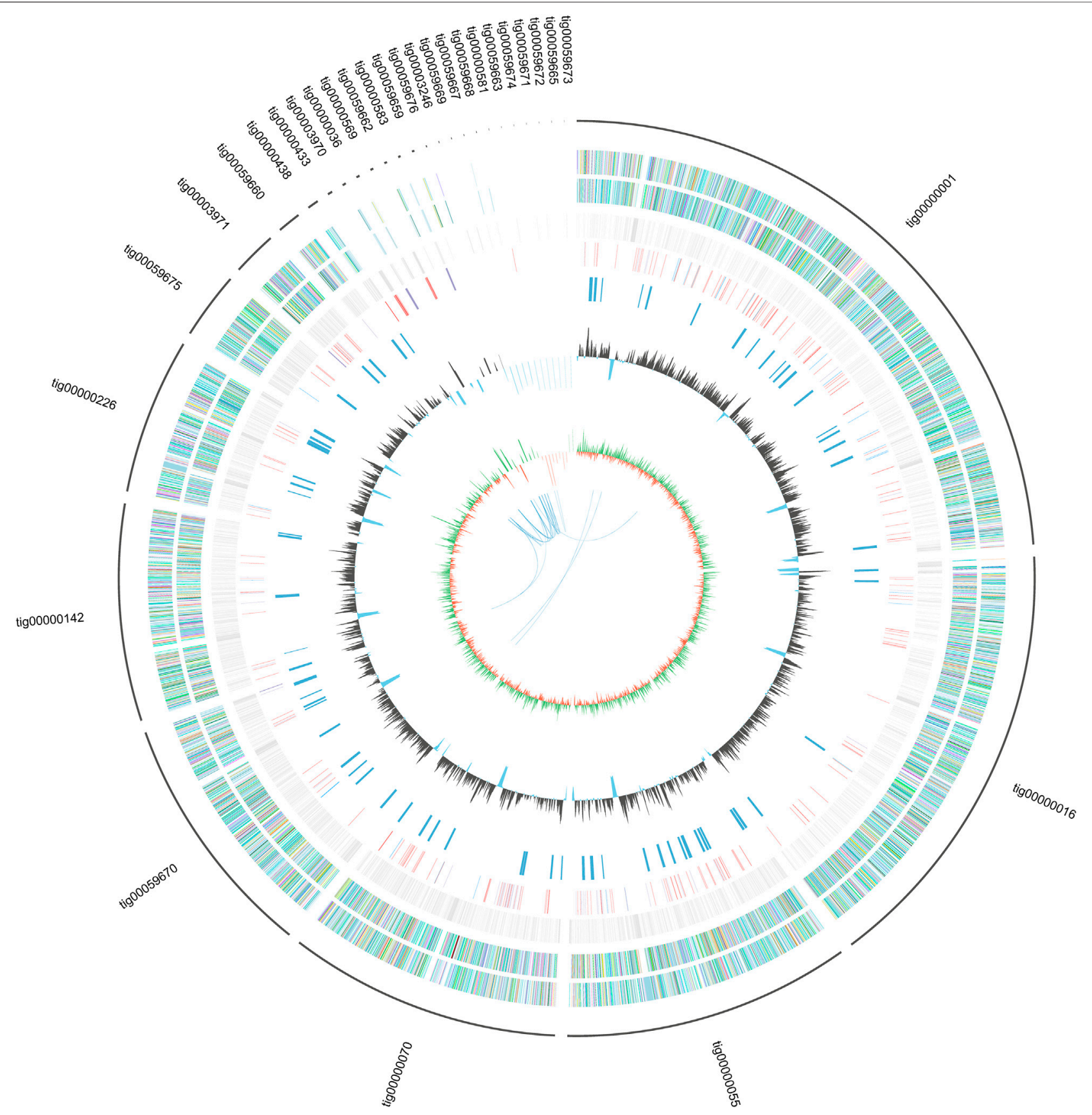

FIGURE 1 | General genome features of marine strain Aspergillus niger L14 (From the inside out: In-paralog pairs; GC skew, the green part represent positive value while the orange part represent negative value; $\mathrm{G}+\mathrm{C} \%$; SMs gene clusters; ncRNA; repeat; minus strand coding sequence (CDS) annotation; plus strand CDS annotation; scaffolds).

It is a matter of controversy that some $A$. niger isolates are renowned for biosynthesis of valuable natural products of nutritional, agrochemical, and pharmaceutical interest, while others are reputed to cause the "black mold" disease (Hayden et al., 1994; Ozer and Koycu, 2006) and produce a plethora of mycotoxins (Sanchez et al., 2012). A. niger possesses a bulk warehouse of prolific genes, which involve in regulation of primary and secondary metabolisms (Pel et al., 2007). A genome-scale metabolic network for $A$. niger has been established on account of its high efficiency in rational metabolic design and systems biology studies, such as strain improvement and process optimization (Sun et al., 2007; Lu 
TABLE 1 | General genomic features of 12 Aspergillus niger strains from NCBI database.

\begin{tabular}{|c|c|c|c|c|c|c|c|c|}
\hline Strain & Genome size (Mb) & $\mathbf{G}+\mathbf{C} \%$ & Scaffold & Gene & tRNA & $\begin{array}{l}\text { Protein-coding } \\
\text { genes }\end{array}$ & Isolation source & Assembly ID \\
\hline ATCC 1015 & 34.8 & 50.3 & 24 & 10947 & - & 10950 & - & GCA_000230395.2 \\
\hline CBS 513.88 & 34.0 & 50.4 & 20 & 10828 & 263 & 14165 & - & GCA_000002855.2 \\
\hline $\mathrm{SH}-2$ & 34.6 & 50.3 & 349 & - & - & - & Soil & GCA_000633045.1 \\
\hline ATCC 13496 & 35.7 & 49.5 & 133 & 12468 & 273 & 12194 & - & GCA_003344705.1 \\
\hline An76 & 34.9 & 49.4 & 669 & 10373 & - & 10373 & Soil & GCA_001515345.1 \\
\hline $\begin{array}{l}\text { JSC- } \\
093350089\end{array}$ & 36.1 & 49.5 & 223 & - & - & - & $\begin{array}{l}\text { International space station environmental } \\
\text { surface }\end{array}$ & GCA_001931795.1 \\
\hline H915-1 & 36.0 & 49.2 & 30 & - & - & - & Soil & GCA_001741905.1 \\
\hline L2 & 36.4 & 49.2 & 30 & - & - & - & Soil & GCA_001741915.1 \\
\hline A1 & 34.6 & 50.1 & 319 & - & - & - & Soil & GCA_001741885.1 \\
\hline MOD1-FUNGI2 & 33.8 & 50.4 & 3199 & - & - & - & Red seedless grapes & GCA_004634315.1 \\
\hline RAF 106 & 35.1 & 49.1 & 10 & - & - & - & Pu-er tea & GCA_011316255.1 \\
\hline L14 & 36.1 & 49.3 & 30 & 11524 & 296 & - & Marine sponge & JADEYYF000000000 \\
\hline
\end{tabular}

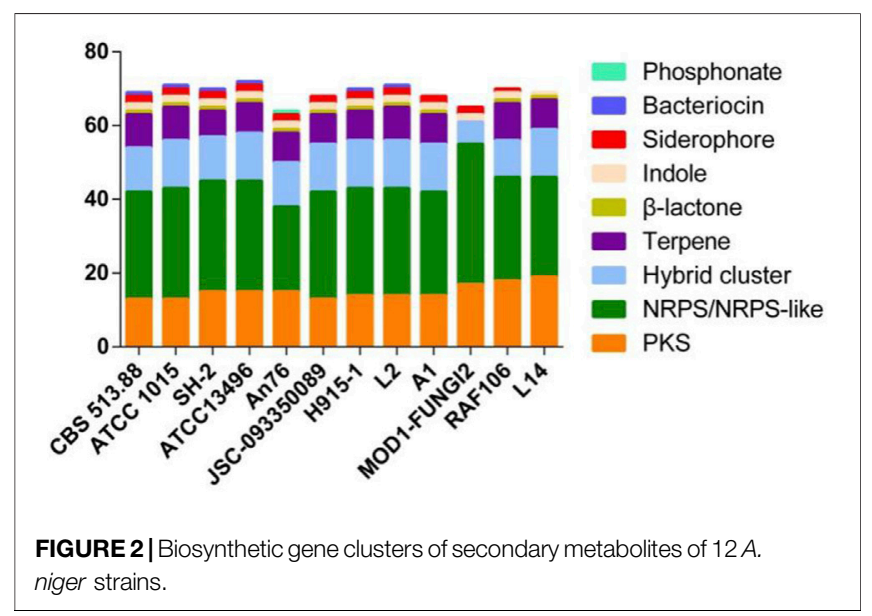

et al., 2017). Numerous $A$. niger strains have been applied in many fields for a long time. For instance, citric acid as one of incredible organic acids in food industry had been produced on a large scale by $A$. niger 100 years ago (Cairns et al., 2018; Li et al., 2020). It is important that $A$. niger is one of the excellent producers of valuable proteases, which had been widely used as detergents and food ingredients and additives, such as acetylesterase, amylase, fucosidase, glucose oxidase, glucosidase, mannanase, phospholipase, phytase, prolyl endopeptidase, triacylglycerol lipase, trehalase, and xylanase. In addition, numerous chemical studies have indicated that $A$. niger is one of the rich sources of bioactive SMs, with great potential application in agriculture and medicine. Moreover, endoxylanase isozymes of $A$. niger have great potential transforming lignocellulose in pulp and paper industry as industrial bleaching aids (Duarte and Costaferreira, 1994). Furthermore, A. niger is also able to deal with the phenolic contaminants in waste water of fermentation broth from industry (Duarte and Costaferreira, 1994). Since genetic engineering is inefficient for fully exploiting in the filamentous fungi industry, a CRISPR (clustered regularly interspaced short palindromic repeats)-Cas9 system had been developed (Nødvig et al., 2015; Nødvig et al., 2018). Based on these genome-editing toolbox, gene inactivation and knockout, gene insertion, base editing, promoter replacement, and regulation of gene expression in $A$. niger have come true. In the future, more importance may be focused on traceless gene editing, multiple gene editing and fine regulation of gene expression in A. niger.

\section{SECONDARY METABOLITES FROM ASPERGILLUS NIGER}

By extensive search on the database of Dictionary of Natural Products (DNP), as many as $166 \mathrm{~A}$. niger-derived secondary metabolites (1-166) were detected till 2020. On the basis of chemical structures, these chemicals are grouped into five types: pyranone, alkaloid, cyclopentapeptide, polyketide, and sterol and, respectively, introduced as follows. (More detailed information about these substances is provided in the Supplementary Materials (Supplementary Table S3).)

\section{Pyranones}

\section{$\gamma$-Naphthylpyradone Monomers}

Pyranone derivatives are the most isolated SMs from A. niger, including $\gamma$-naphthylpyradones (1-31), a-pyranones (32-56), and $\gamma$-pyranones (57-60). A. niger-derived naphthylpyradones are sorted into two classifications: monomers and dimers, with linear and angular naphtho- $\gamma$-pyrone. Fonsecin (1) is one of the most frequently isolated $\gamma$-naphthylpyradone produced by several $A$. niger strains from various sources, including terrestrial soil (Sakurai et al., 2002), marine (Leutou et al., 2016; Zhou et al., 2016), and plants (Bouras et al., 2005; Fernand et al., 2017; Akinfala et al., 2020). Biological tests suggested that compound 1 possesses dose-dependent inhibitory effect on the interleukin-4 (IL-4) signal transduction and stronger radical scavenging activity against 2,2-diphenyl-1picrylhydrazyl (DPPH) than ascorbic acid (Sakurai et al., 2002; Leutou et al., 2016). Two analogs TMC-256A1 (3) and TMC$256 \mathrm{C} 1$ (8) also effectively inhibited the IL-4 driven luciferase (Sakurai et al., 2002). However, fonsecin B (2) and nigerasperone A (4) exhibited weak bioactivity against luciferase and DPPH 


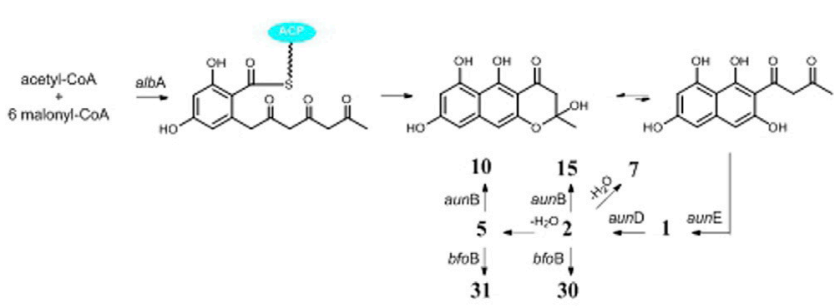

FIGURE 3 | Proposed biosynthetic pathway of $\gamma$-naphthylpyridones.
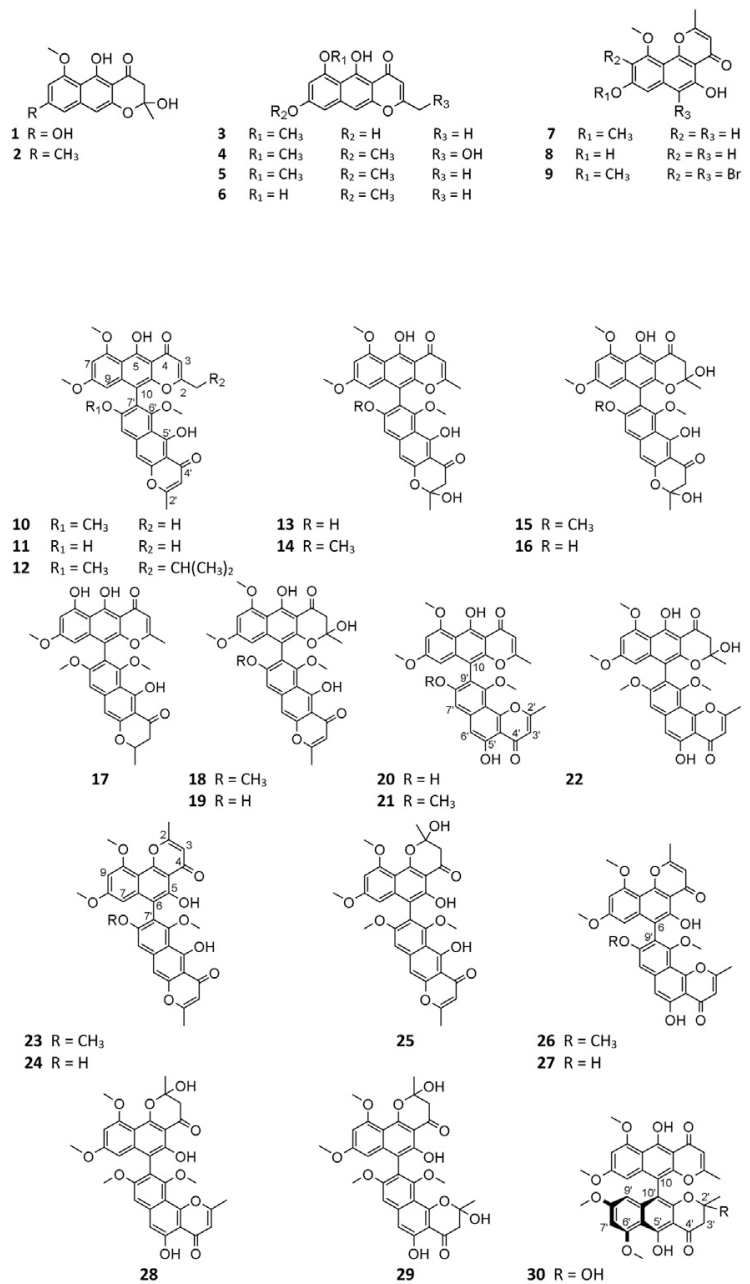

22

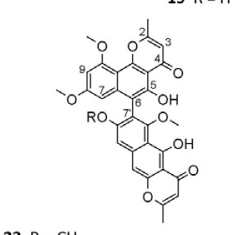

$23 \mathrm{R}=\mathrm{CH}$
$24 \mathrm{R}=\mathrm{H}$

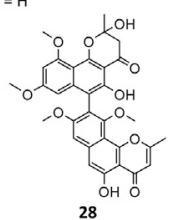

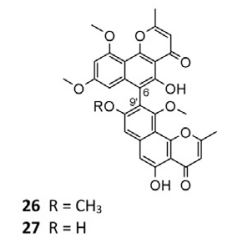

$$
27 \mathrm{R}=\mathrm{H}
$$

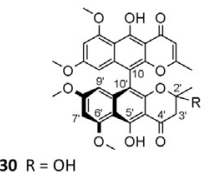

$31 \mathrm{R}=\mathrm{H}$

(Sakurai et al., 2002; Zhang et al., 2007b). One new cytotoxic and antimicrobial rubrofusarin B (5) was purified from strain IFBE003 endophytic on Cynodon dactylon Linn. (Song et al., 2004). When cultivated in $\mathrm{NaBr}$ or $\mathrm{CaBr}_{2}$-containing medium, one marine-derived strain MSA773 was found to secrete a new brominated derivative 6,9-dibromoflavasperone (9) with potent radical scavenging activity (Leutou et al., 2016).

\section{$\gamma$-Naphthylpyradone Dimers}

A. niger-derived dimeric naphthylpyradones (10-31) consist of two monomers with linear and/or angular structure(s). It is interesting that most of these bis-naphtho- $\gamma$-pyrones were produced by symbiotic $A$. niger strains. Chemical investigation of eight $A$. niger strains led to isolation of the same SM aurasperone A (10) (Tanaka et al., 1966; Tanaka et al., 1972; Akiyama et al., 2003; Zhang et al., 2007b; Fang et al., 2016; Li et al., 2016; Wang et al., 2018; Padhi et al., 2020), which possessed a broad spectrum of bioactivities including moderate cytotoxicity (Fang et al., 2016; Padhi et al., 2020), strong antimicrobial effect (Lu et al., 2014; Padhi et al., 2020), and xanthine oxidase (XO) inhibitory and anti-hyperuricosuric activity (Song et al., 2004). Aurasperone $\mathrm{B}(\mathbf{1 5})$ had potent radical scavenging activity against DPPH with an $\mathrm{IC}_{50}$ value of $0.01 \mu \mathrm{M}$ (Leutou et al., 2016). Marine strain SCSIO Jcsw6F30 was a prolific producer of asperpyronetype bis-naphtho- $\gamma$-pyrones (BNPs) 10, 13-16, 18, 20-22, 24, and 27, among which compounds 13, 16, and 20 exhibited remarkable inhibitory effects on COX-2 (Fang et al., 2016). In addition to nigerasperone $\mathrm{A}$ (4), two dimeric naphthylpyradones nigerasperones B (29) and C (19) were obtained from strain EN-13 and shown to exhibit a moderate radical scavenging effect on DPPH (Zhang et al., 2007b). Bioassay-guided fractionation of the crude extract of strain AKRN associated with Entandrophragma congoënse afforded a new antibacterial naphtho- $\gamma$-pyrone dimer 2hydroxydihydronigerone (30) (Happi et al., 2015).

One possible pathway for biosynthesis of $\gamma$-naphthylpyradone derivatives had been first proposed by Obermaier and Muller (2019). As shown in Figure 3, one acetyl-CoA and six malonylCoA clusters were used as substrates for the biosynthesis of compounds 1-3 and 8 by successive catalytic reactions in a nonreducing PKS (nrPKS) system. Two of these monomers further dimerized at various carbon positions (C-6, C-7, C-9, or $\mathrm{C}-10$ ) and resulted in the formation of dimers $16,21,27$, and 28. Lately, one nrPKS gene D8.t287 responsible for the biosynthesis of the initial precursor heptaketone was identified and characterized by target gene knockout experiment and UPLC-MS analysis (Hua et al., 2020). However, the role of the gene $A u n B$ or $B f o B$ is not confirmed so far.

\section{$\alpha$-Pyranones}

A. niger-derived a-pyranones contain 14 monocyclic compounds (32-40,50), 7 dicyclics $(41-47,51)$, three tricyclics $(48,49$, and 56), and four tetracyclics (52-55). Chemical analysis of an endophytic $A$. niger strain colonizing in liverwort Heteroscyphus tener (Steph.) Schiffn resulted in isolation of three new amide campyrones A-C (38-40) together with compounds 33 and 34 (Talontsi et al., 2013; Li et al., 2015). One possible biosynthetic pathway proposed by Reber and Burdge (2018) suggested that compounds 38-40 were, respectively, formed by one malonyl-CoA and three $\mathrm{N}$-acetyl aliphatic amino acids including $L$-valine, $L$-leucine, and $L$-isoleucine (Figure 4), along with two congeners asnipyrones $\mathrm{A}$ (42) and $\mathrm{B}$ (46) and nigerapyrones $\mathrm{A}-\mathrm{H}$ (35-37, 43-45, 48-49) were first discovered from a mangrove plant-derived strain MA-132 (Liu et al., 2011). 


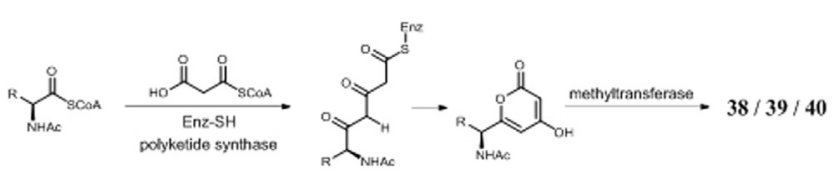

FIGURE 4 | Proposed biosynthetic pathway of campyrones.

Unfortunately, none of these compounds showed potent cytotoxic or antimicrobial activities. Nafuredin (50) and bicoumanigrin (52) were new a-pyranone analogs produced by marine sponge-derived $A$. niger strains; the former exhibited a powerful and selective inhibitory effect on NFRD (NADH-fumarate reductase) (Takano et al., 2001; Ui et al., 2001) and the latter 3,3'-bicoumarin had moderate cytotoxicity against leukemia and carcinoma cell lines (Hiort et al., 2004). Three 8,8'-bicoumarins, orlandin (53), kotanin (54), and 7-desmethyl-kotanin (55) were produced by a number of $A$. niger strains from various sources, and 53 showed potent inhibitory activity against wheat coleoptile growth at $1 \mathrm{mM}$ but not toxic to day-old cockerels (Cutler et al., 1979; Ovenden et al., 2004; Sorensen et al., 2009; Jomori et al., 2020). Biosynthetically, one acetyl-CoA and four malonyl-CoAs comprised one coumarin through several successive reactions catalyzed by PKSs, followed by formation of compounds 52-55 through dimerization (Figure 5) (Huttel et al., 2003; Huttel and Muller, 2007; Girol et al., 2012). In this pathway, PKS gene ktnS was responsible for origination of dimeric coumarins 52-55, gene $k t n B$ encode $\mathrm{O}$-methyltransferase, and gene $k t n C$ encode CYP450 monooxygenase, manipulating the dimerization of 52-55.

\section{$\gamma$-Pyranones}

To the best of our knowledge, only four $\gamma$-pyranone derivatives (57-60) had been detected in SM of A. niger. Among these substances, kojic acid (57) is the most common product with weak antimicrobial property (Liu et al., 2011; Happi et al., 2015; Padhi et al., 2020). In addition to carbonarone A (59) and tensidol B (60), one new benzyl $\gamma$-pyranone nigerpyrone (58) was discovered from a mutant strain FGSC A1279 $\Delta \mathrm{gcnE}$ and was found to have potent and selective activity against Candida parapsilosis (Wang et al., 2018; Padhi et al., 2020).

\section{Alkaloids}

\section{Pyrroles}

Pyranonigrin derivatives (61-69) are a family characterized by pyrano [2,3-b] pyrrole skeleton, and their biosynthesis are

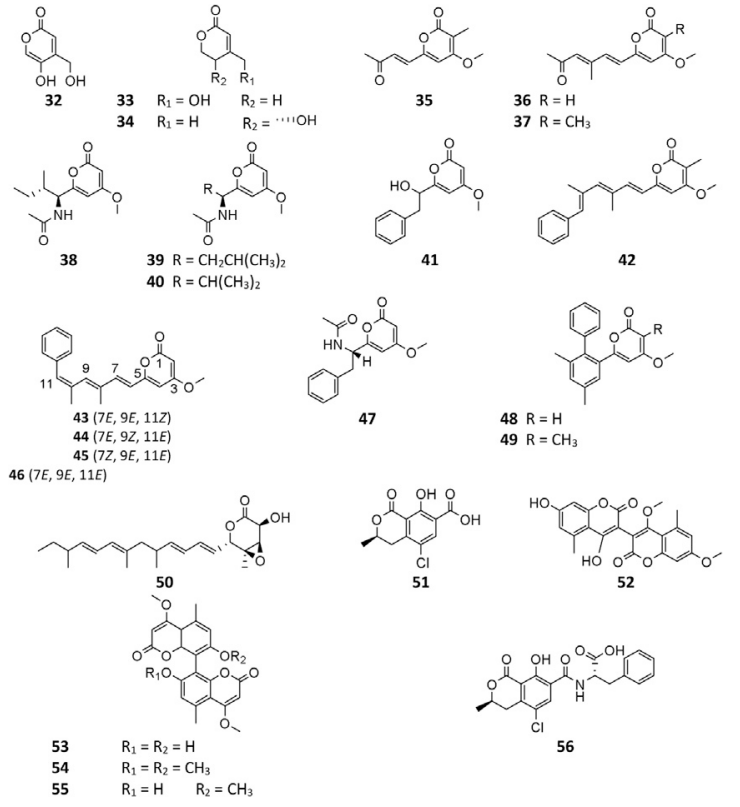

manipulated by the pyn gene cluster in A. niger (Riko et al., 2014; Yamamoto et al., 2015). Chemical investigation of one marine sponge-derived strain afforded four pyranonigrins B-D $(61,62,64)$ and $A b(63)$, which 63 showed a strong inhibitory effect on the growth of neonate larvae of the plant pest insect Spodoptera littoralis (Hiort et al., 2004). Pyranonigrins A (65), S (66), and E (67) were important agents with potent radical scavenging activity toward DPPH and superoxide (Miyake et al., 2007; Riko et al., 2014). One possible biosynthetic pathway of pyranonigrin E (67) had been first proposed by Yamamoto et al. (2015) and coworker in 2015, in which the start units contained one acetyl-CoA, six malonyl-CoAs, and one L-Ser (Figure 6), under the action of gene pynA (PKS-NRPS hybrid synthase), pynI (encode thioesterase), pynC (encode methyltransferase), pynG (encode flavin-dependent oxidase), pynD (encode CYP450), and pynH (encode aspartyl protease). After non-enzymatic reaction, two pyranonigrin $\mathrm{E}$ (67) units could be dimerized to form pyranonigrin F (69). One soilderived $A$. niger strain was found to produce a new dichlorinated pyrrole pyoluteorin (70), which obviously induced cell cycle arrest and apoptosis in human triplenegative breast cancer cells MDA-MB-231 (Ding et al., 2020). Two benzyl furopyrrols tensidols A (71) and B (72) from strain

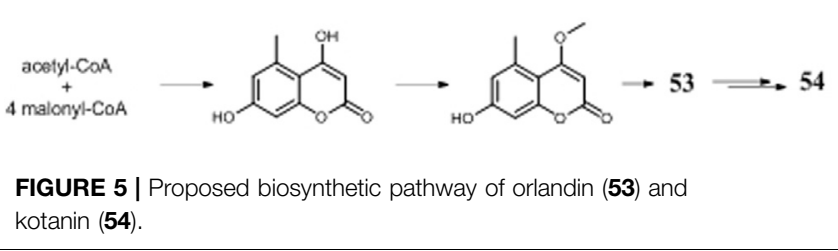

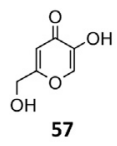

57

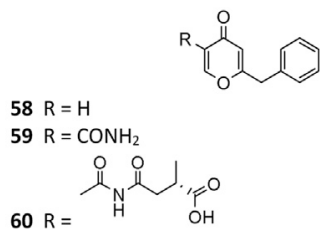




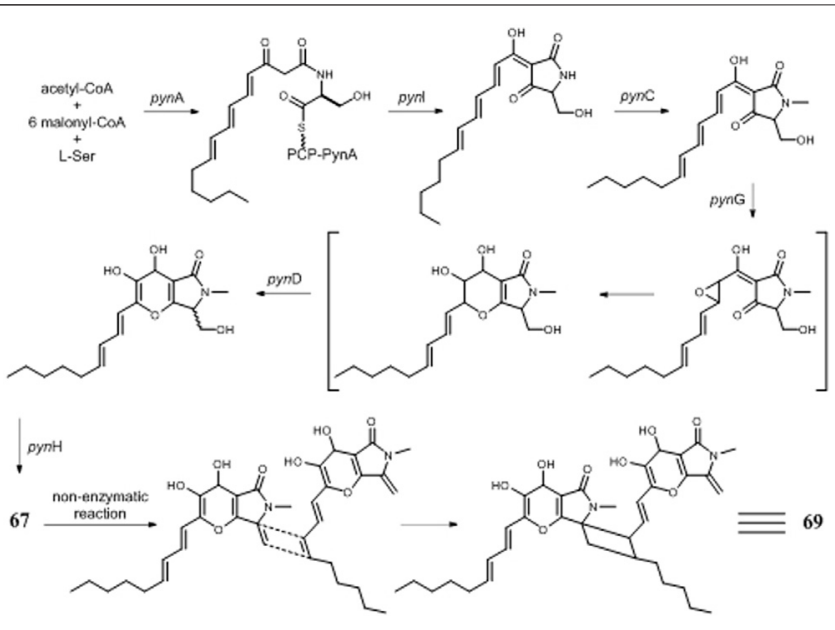

FIGURE 6 | Proposed biosynthetic pathway of pyranonigrin E (67) and pyranonigrin $F(69)$.

FKI-2342 were potentiators of antifungal miconazole activity (Fukuda et al., 2006) and lately corrected as compounds $\mathbf{5 9}$ and 60 (Henrikson et al., 2011).

\section{Pyridones}

A. niger-derived pyridone derivatives (73-82) have one benzyl group and possess antimicrobial and cytotoxic properties (chatr 4). Two new a-pyridones aspernigrins $\mathrm{A}$ (73) and $\mathrm{B}_{\mathrm{b}}$ (74) were isolated from one $A$. niger strain of marine sponge Axinella damicornis and showed moderate cytotoxicity and a potent neuroprotective effect, respectively, (Hiort et al., 2004). When cultivated in fermentation medium containing suberoylanilide hydroxamic acid (SAHA) and p-fluoro SAHA, strain ATCC 1015 was discovered to produce three antifungal $\gamma$-pyridones, nygerones A (78), B (75), and p-fluoro nygerone B (77) (Henrikson et al., 2009; Henrikson et al., 2011). In addition to three $\gamma$-naphthylpyradones $(\mathbf{1}, \mathbf{3}$, and 5$)$ and one cyclic peptide (111), three 2-benzyl- $\gamma$-pyridones aspernigrins B-D (80-82) were obtained from the marine strain SCSIO Jcsw6F30, and $\mathbf{8 1}$ was found to have potent inhibitory activity toward HIV-1 SF162infected TZM-bl cells (Zhou et al., 2016).

\section{Other Alkaloids}

Three fatty amines fumonisins $B_{2}(\mathbf{8 3}), B_{1}(\mathbf{8 4})$, and $B_{4}(\mathbf{8 5})$ from stains FGSC A1279 and IBT 28144 were carcinogenic (Nielsen et al., 2009; Sorensen et al., 2009; Li et al., 2019). The aza gene cluster in strain ATC C1015 was found be responsible for biosynthesis of azanigerone D (86) (Zabala et al., 2012). In addition to pyoluteorin (70), phenazine-1-carboxylic acid (87) was produced by the soil $A$. niger strain (Ding et al., 2020). Two new piperazines nigragillin (88) and nigerazine B (89) were purified from strain ATCC 11414, and their biosynthesis were regulated by the naphthopyrone precursor BGC alb gene cluster (Chiang et al., 2011). Endophytic strain IFB-E003-derived aspernigerin (90) displayed a potent effect on the tumor cell lines nasopharyngeal epidermoid $\mathrm{KB}$, cervical carcinoma Hela, and colorectal carcinoma SW1116 (Shen et al., 2006).

\section{Amides}

Till the end of 2020, only six amides (91-96) had been isolated and characterized from $A$. niger strains. Fractionation of crude extract of marine strain BRF-074A afforded one furan ester derivative (91), one cerebroside chrysogeside $\mathrm{D}$ (93), and two spiro amides pseurotins A (95) and D (96), among which 91 exerted a cytotoxic effect on HCT-116 cell line (Uchoa et al., 2017). When cultivated on wheat bran, strains CFR-W-105 and MTCC-5166 were discovered to produce nigerloxin (92) with free radical DPPH scavenging activity and inhibitory effect on lipoxygenase-I (LOX-1) and rat lens aldose reductase (RLAR) (Rao et al., 2002; Chakradhar et al., 2009). Ergosterimide (94) was a new natural Diels-Alder adduct of ergosteroid and maleimide produced by the strain EN-13 from marine alga (Zhang et al., 2007a).

\section{Cyclopeptides}

All peptides of $A$. niger are cyclic and consist of ten dipeptides (97-106), eight pentapeptides (107-114), and three bis(dipeptide)s (115-117). In addition to a-pyranones 32-34, 38 , and 40 , four diketopiperazines $(97,99,115$, and 116) were isolated from an endophytic strain of liverwort Heteroscyphus tener (Steph.). Schiffn, and compounds 115 and 116 showed weak activity against the human ovarian carcinoma cancer cell line A2780 (Li et al., 2015). However, 115 exhibited significant selective cytotoxicity to human leukemia murine colon 38 and human colon H116 and CX1 cell lines (Varoglu et al., 1997; Varoglu and Crews, 2000). One strain BRF-074A from Northeast Brazilian coast was a prolific producer of cyclopeptides (101-107, 114) (Uchoa et al., 2017). Phytochemcial analysis of an uncoded marine strain afforded a new diketopiperazine dimer (117) and nine monomers (98-106) (Ovenden et al., 2004; Zhang et al., 2010; Uchoa et al., 2017). Compounds 98 and 99 had been reported to regulate plant growth (Kimura et al., 1996; Kimura et al., 2005), and $\mathbf{1 0 1}$ had selectively potential cytotoxicity (Graz et al., 2000). Eight malformin analogs (107-114) were a group of SMs containing structural skeleton of cyclo- $D$ cysteinyl- $D$-cysteinyl- $L$-amino acid- $D$-amino acid- $L$-amino acid (Kim et al., 1993). Malformin A (107) demonstrated antibacterial (Suda and Curtis, 1966; Liu et al., 2013) and
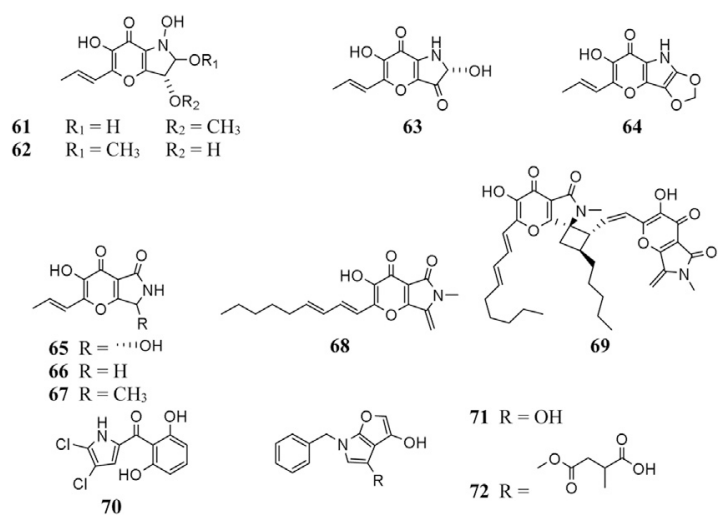

$72 \mathrm{R}=\mathrm{OH}$ 


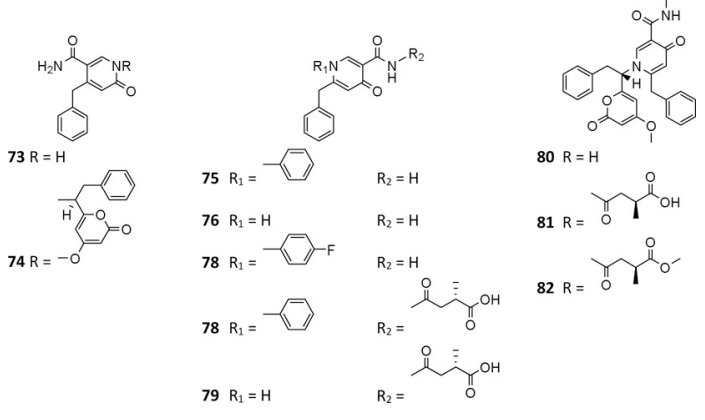

anticancer activities (Wang et al., 2015), while malformin C (114) exhibited a broad spectrum of biological properties including anti-HIV-1 (Zhou et al., 2016), cytotoxic (Jomori et al., 2020), anticancer (Wang et al., 2015), and antibacterial (Suda and Curtis, 1966; Liu et al., 2013).

\section{Polyketides}

Polyketides (118-155) are the largest group of SMs produced by A. niger. Citric acid (118) and itaconic acid (119) have been large-scale products in food and pharmaceutical industry for decades (Andersen et al., 2011; Li et al., 2012). Some other valuable chemicals with low molecular weight are also produced by $A$. niger, such as 2-phenylethanol (128) (Etschmann et al., 2015), p-hydroxyphenylacetic acid (129) (Happi et al., 2015), gallic acid (130) (Saeed et al., 2020), benzoic acid derivative (131) (Zabala et al., 2012), and asperyellone (147) (Jefferson, 1967; Chidananda et al., 2008). In comparison with 119, the biological activity of hexylitaconic acid (120) dramatically attenuated (Varoglu et al., 1997; Varoglu and Crews, 2000). By overexpression of transcriptional regulator $\mathrm{pBARAGA}-\mathrm{CaaR}$ of BGC caa in glucose minimal medium, strain ATC C1015 successfully produced three acyltetronic acid derivatives carlosic acid (123), carlosic acid methyl ester (124), and agglomerin F (125) (Yang et al., 2014). Chemical analysis of two strains KB1001 and F97S11 afforded fifteen meroterpenoid derivatives (132-146), in which biosynthesis was deduced to be manipulated by the yan gene cluster in strain KB1001 (Figure 7) (Bugni et al., 2000; Holm et al., 2014). Furthermore, yan gene cluster consisted of gene yanA [encode 6-methylsalicylic acid synthase (6-MSAS)] together with eight additional genes yanB (encode decarboxylase), yanC (encode CYP450), yanD (encode dehydrogenase), yanE (unknown), yanF (encode oxidase), yanI

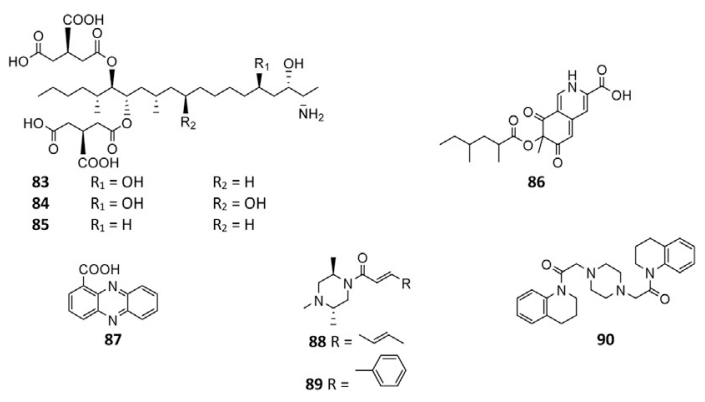

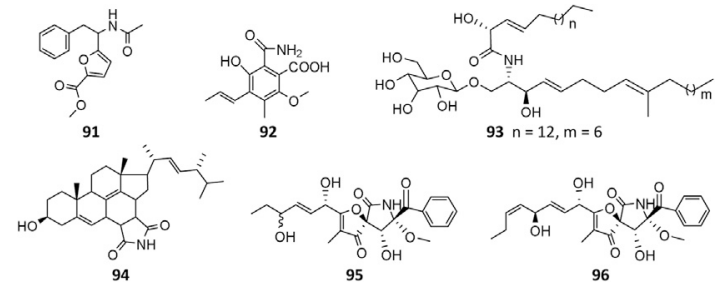

(encode O-mevalon tiransferase), yanH (encode CYP450), and yan $G$ (encode prenyl transferase).

Asperyellone (147) was the common product of strains NRRL3 and CFTRI 1105 (Jefferson, 1967; Chidananda et al., 2008) and exhibited inhibitory effect on lipoxygenase and human platelet aggregation (Rao et al., 2002), UVB protection (Santhakumaran et al., 2019), and antifungal activity (Ayer et al., 1996). In addition
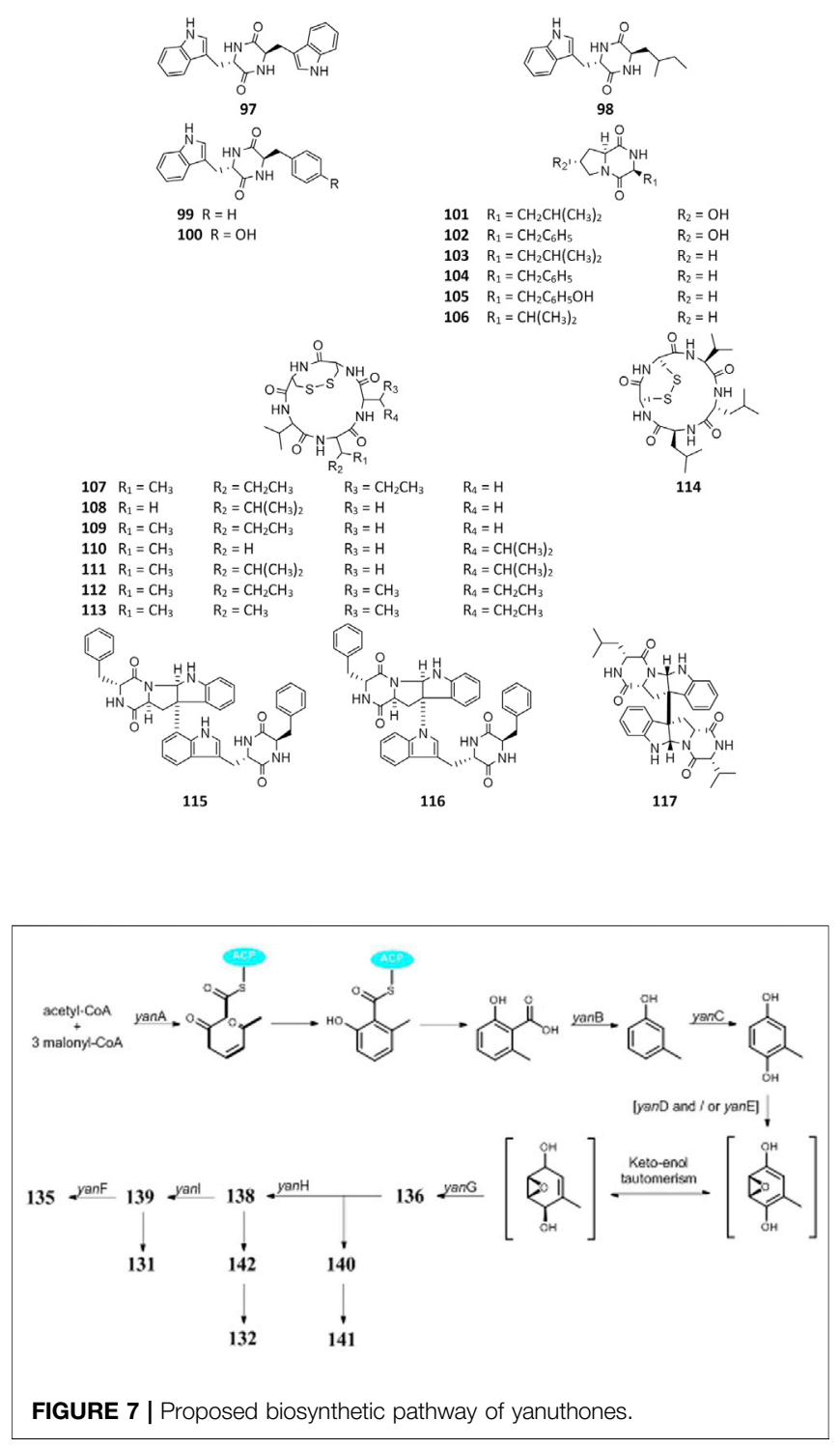


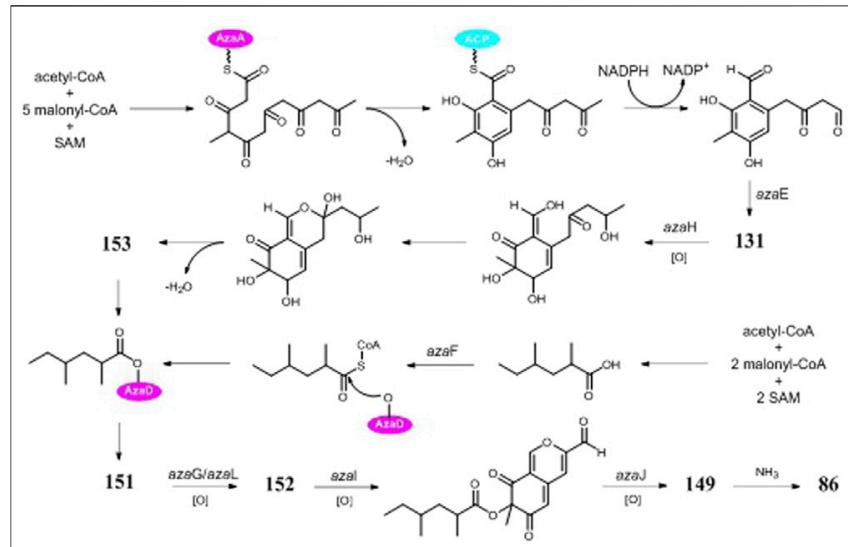

FIGURE 8 | Proposed biosynthetic pathway of pyranoquinones in strain ATCC 1015.
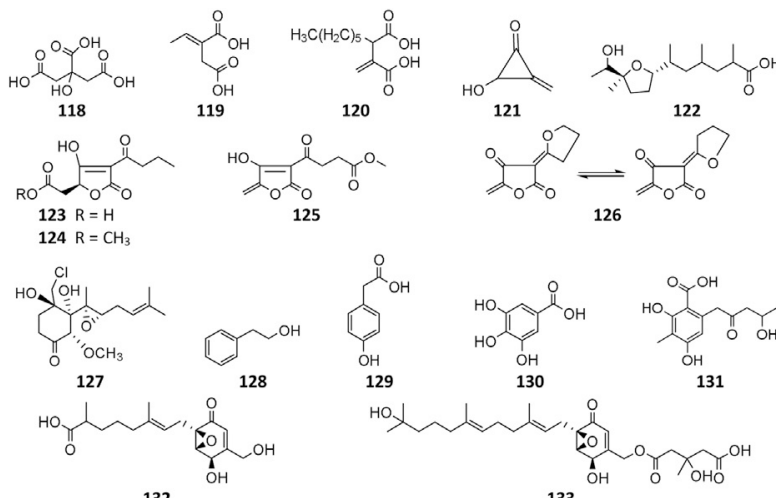

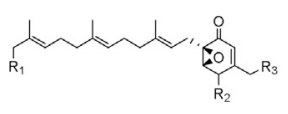

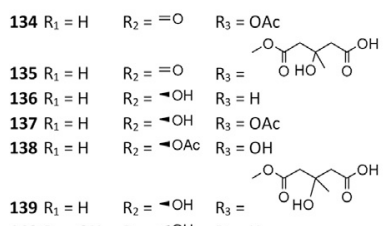<smiles></smiles>

147

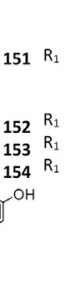

156

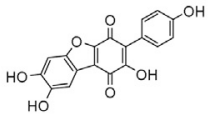

157

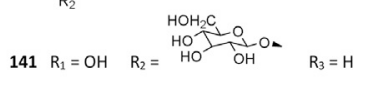

$142 \mathrm{R}_{1}=\mathrm{OH} \quad \mathrm{R}_{2}=-\mathrm{OH}$ $143 \mathrm{R}_{1}=\mathrm{OH} \quad \mathrm{R}_{2}=-\mathrm{OH}$ $144 R_{1}=O H \quad R_{2}=-O A C$ $145 R_{1}=H \quad R_{2}=-O H$ $146 R_{1}=H \quad R_{2}=$ 只

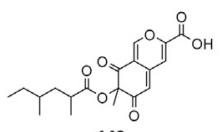

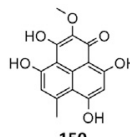

150

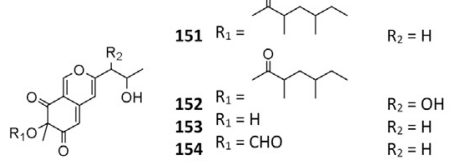<smiles>O=C(OCc1ccc(O)cc1)C(O)c1ccc(O)cc1</smiles>
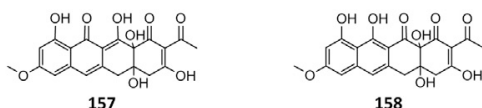

158

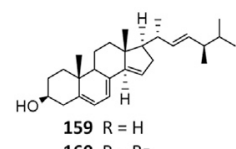

$160 R=B 2$

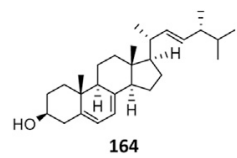

164

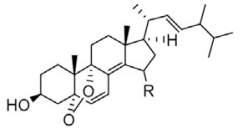

$161 \mathrm{R}=\alpha-\mathrm{OH}$

$162 \mathrm{R}=\beta-\mathrm{OH}$

165

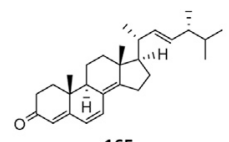

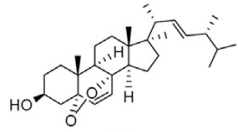

163

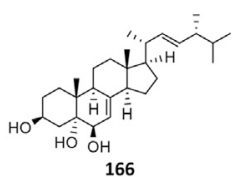

to $\gamma$-pyridone (86), five highly oxygenated pyranoquinones (86, 149, and 151-154) were detected in SMs of strain T1 by activation of the aza gene cluster (Zabala et al., 2012) (Figure 8). In biosynthesis of pyranoquinones, genes azaE (encode ketoreductase), $a z a F$ (encode acyl:CoA ligase), $a z a G$ (encode FAD-dependent oxygenase), azaH (encode salicylate monooxygenase), azaI (encode CYP450), azaJ (encode dehydrogenase), and azaL (encode FAD-dependent oxygenase) play important roles. Funalenone (150), one phenalene derivative, was obtained from strain ATCC 11414 whether the albA gene was auxotrophic or not (Chiang et al., 2011). Meanwhile, funalenone (150) was also found in A. niger mutant $\Delta g c n \mathrm{E}$ (strain FGSC A1279 lacking epigenetic regulatorgc $\mathrm{E}$ ) (Wang et al., 2018). Two tetracycline analogs BMS-192548 (157) and TAN-1612 (158) were, respectively, obtained from strains WB2346 and ATC C1015 and shown to be acyclic binding inhibitors of neuropeptide Y receptors (Kodukula et al., 1995; Shu et al., 1995; Li et al., 2011).

\section{Sterols}

As the by-product of manufacture of citric acid, 14dehydroergosterol (159) and its benzoate (160) were the first steroids isolated from A. niger (Barton and Bruun, 1951) and possessed anti-inflammatory and cytotoxic properties (Ano et al., 2017). Strain MA-132-derived nigerasterols A (161) and B (162) had potent antiproliferative activity against human promyelocytic leukemia (HL60) and human lung carcinoma (A549), with IC $_{50}$ values of 0.11 and $0.43 \mu \mathrm{M}$, respectively, (Liu et al., 2013). In addition to ergosterimide (94), four steroid derivatives (163-166) were discovered from the endophytic strain EN-13 associated with marine brown alga (Zhang et al., 2007a).

\section{CONCLUSION AND FUTURE PROSPECTS}

A. niger strains are ubiquitous in nature and occupy a wide spectrum of habitats in animal and plant environments, and they are economically important both as harmful or beneficial microorganisms. Numerous chemical studies suggest that $A$. niger is one of the prolific sources of functional biomolecules, including organic acids, vitamins, pesticides, valuable proteases, and therapeutic agents, which have potential 
application in various fields including agriculture, food industry, and medicine. However, the number of new bioactive compounds from $A$. niger has been decreasing for the past 5 years. This deteriorating trend will result in a negative impact on discovery and development of new $A$. niger-derived valuable substances, such as new drug leads. Therefore, more efforts should be made to explore more sources for isolation of new A. niger strains and to awaken their silent BGCs to manufacture novel functional biomolecules using new strategies, such as one strain many compounds (OSMAC) approach (Hemphill et al., 2017; Pan et al., 2019) and genetic mining combined with metabolic engineering (Zhang et al., 2019; Li et al., 2020; Wei et al., 2021). Moreover, functional genomics should allow for an in-depth understanding of the underlying biosynthetic logic of A. niger-derived SMs (He et al., 2018). In order to accelerate development of valuable products from A. niger, construction and breeding of robust strains as well as optimization of their cultivation and fermentation processes should be intensively conducted at various levels (Zou et al., 2015; Xu et al., 2019).

\section{REFERENCES}

Akinfala, T. O., Houbraken, J., Sulyok, M., Adedeji, A. R., Odebode, A. C., Krska, R., et al. (2020). Moulds and Their Secondary Metabolites Associated with the Fermentation and Storage of Two cocoa Bean Hybrids in Nigeria. Int. J. Food Microbiol. 316, 108490. doi:10.1016/ j.ijfoodmicro.2019.108490

Akiyama, K., Teraguchi, S., Hamasaki, Y., Mori, M., Tatsumi, K., Ohnishi, K., et al. (2003). New Dimeric Naphthopyrones from Aspergillus niger. J. Nat. Prod. 66 (1), 136-139. doi:10.1021/np020174p

Andersen, M. R., Salazar, M. P., Schaap, P. J., van de Vondervoort, P. J. I., Culley, D., Thykaer, J., et al. (2011). Comparative Genomics of Citric-Acid-Producing Aspergillus niger ATCC 1015 versus Enzyme-Producing CBS 513.88. Genome Res. 21 (6), 885-897. doi:10.1101/gr.112169.110

Ano, Y., Ikado, K., Shindo, K., Koizumi, H., and Fujiwara, D. (2017). Identification of 14-dehydroergosterol as a Novel Anti-inflammatory Compound Inducing Tolerogenic Dendritic Cells. Sci. Rep. 7. doi:10.1038/ s41598-017-14446-1

Ayer, W. A., Muir, D. J., and Chakravarty, P. (1996). Phenolic and Other Metabolites of Phellinus Pini, a Fungus Pathogenic to pine. Phytochemistry 42 (5), 1321-1324. doi:10.1016/0031-9422(96)00125-2

Barton, D. H. R., and Bruun, T. (1951). 607. A New Sterol from a Strain of Aspergillus niger. J. Chem. Soc., 2728. doi:10.1039/jr9510002728

Blin, K., Shaw, S., Steinke, K., Villebro, R., Ziemert, N., Lee, S. Y., et al. (2019). antiSMASH 5.0: Updates to the Secondary Metabolite Genome Mining Pipeline. Nucleic Acids Res. 47 (W1), W81-W87. doi:10.1093/nar/gkz310

Bouras, N., Mathieu, F., Coppel, Y., and Lebrihi, A. (2005). Aurasperone F - a New Member of the Naphtho-Gamma-Pyrone Class Isolated from a Cultured Microfungus,Aspergillus nigerC-433. Nat. Product. Res. 19 (7), 653-659. doi:10.1080/14786410412331286955

Bugni, T. S., Abbanat, D., Bernan, V. S., Maiese, W. M., Greenstein, M., Van Wagoner, R. M., et al. (2000). Yanuthones: Novel Metabolites from a Marine Isolate ofAspergillusniger. J. Org. Chem. 65 (21), 7195-7200. doi:10.1021/ jo0006831

Cairns, T. C., Nai, C., and Meyer, V. (2018). How a Fungus Shapes Biotechnology: 100 Years of Aspergillus niger Research. Fungal Biol. Biotechnol. 5, 13. doi:10.1186/s40694-018-0054-5

Chakradhar, D., Javeed, S., and Sattur, A. P. (2009). Studies on the Production of Nigerloxin Using Agro-Industrial Residues by Solid-State Fermentation. J. Ind. Microbiol. Biotechnol. 36 (9), 1179-1187. doi:10.1007/s10295-009-0599-7

\section{AUTHOR CONTRIBUTIONS}

RY made a draft of this review; JL and YW searched and collected all references; HW helped in critical assessing this manuscript; and $\mathrm{HZ}$ conceived and revised this review.

\section{FUNDING}

Financial supports from the National Key R\&D Program of China (2018YFC0311004), the National Natural Science Foundation of China (41776139) and the Fundamental Research Fund for the Provincial Universities of Zhejiang (RFC2019002) were greatly appreciated.

\section{SUPPLEMENTARY MATERIAL}

The Supplementary Material for this article can be found online at: https://www.frontiersin.org/articles/10.3389/fchem.2021.701022/ full\#supplementary-material

Chiang, Y.-M., Meyer, K. M., Praseuth, M., Baker, S. E., Bruno, K. S., and Wang, C. C. C. (2011). Characterization of a Polyketide Synthase in Aspergillus niger Whose Product Is a Precursor for Both Dihydroxynaphthalene (DHN) Melanin and Naphtho- $\gamma$-Pyrone. Fungal Genet. Biol. 48 (4), 430-437. doi:10.1016/ j.fgb.2010.12.001

Chidananda, C., Kumar, C. M., and Sattur, A. P. (2008). Strain Improvement of Aspergillus niger for the Enhanced Production of Asperenone. Indian J. Microbiol. 48 (2), 274-278. doi:10.1007/s12088-008-0026-1

Cutler, H. G., Crumley, F. G., Cox, R. H., Hernandez, O., Cole, R. J., and Dorner, J. W. (1979). Orlandin: a Nontoxic Fungal Metabolite with Plant Growth Inhibiting Properties. J. Agric. Food Chem. 27 (3), 592-595. doi:10.1021/jf60223a043

Ding, T., Yang, L.-J., Zhang, W.-D., and Shen, Y.-H. (2020). Pyoluteorin Induces Cell Cycle Arrest and Apoptosis in Human Triple-Negative Breast Cancer Cells MDA-MB-231. J. Pharm. Pharmacol. 72 (7), 969-978. doi:10.1111/jphp.13262

Duarte, J. C., and Costaferreira, M. (1994). Aspergilli and Lignocellulosics Enzymology and Biotechnological Applications. FEMS Microbiol. Rev. 13 (2-3), 377-386. doi:10.1111/j.1574-6976.1994.tb00038.x

Elissawy, A. M., Ebada, S. S., Ashour, M. L., El-Neketi, M., Ebrahim, W., and Singab, A. B. (2019). New Secondary Metabolites from the Mangrove-Derived Fungus Aspergillus Sp. AV-2. Phytochemistry Lett. 29, 1-5. doi:10.1016/ j.phytol.2018.10.014

Etschmann, M. M. W., Huth, I., Walisko, R., Schuster, J., Krull, R., Holtmann, D., et al. (2014). Improving 2-phenylethanol and 6-Pentyl-a-Pyrone Production with Fungi by Microparticle-Enhanced Cultivation (MPEC). Yeast 32 (1), a-n. doi:10.1002/yea.3022

Fang, W., Lin, X., Wang, J., Liu, Y., Tao, H., and Zhou, X. (2016). AsperpyroneType Bis-Naphtho- $\gamma$-Pyrones with COX-2-Inhibitory Activities from MarineDerived Fungus Aspergillus niger. Molecules 21 (7), 941. doi:10.3390/ molecules21070941

Fernand, M. G., Roullier, C., Guitton, Y., Lalande, J., Lacoste, S., Dupont, J., et al. (2017). Fungi Isolated from Madagascar Shrimps - Investigation of the Aspergillus niger Metabolism by Combined LC-MS and NMR Metabolomics Studies. Aquaculture 479, 750-758. doi:10.1016/j.aquaculture.2017.07.015

Fukuda, T., Hasegawa, Y., Hagimori, K., Yamaguchi, Y., Masuma, R., Tomoda, H., et al. (2006). Tensidols, New Potentiators of Antifungal Miconazole Activity, Produced by Aspergillus niger FKI-2342. J. Antibiot. 59 (8), 480-485. doi:10.1038/ja.2006.67

Girol, C. G., Fisch, K. M., Heinekamp, T., Guenther, S., Huettel, W., Piel, J., et al. (2012). Regio- and Stereoselective Oxidative Phenol Coupling in Aspergillus niger. Angew. Chemie-International Edition 51 (39), 9788-9791. doi:10.1002/ anie. 201203603 
Graz, C. J. M., Grant, G. D., Brauns, S. C., Hunt, A., Jamie, H., and Milne, P. J. (2010). Cyclic Dipeptides in the Induction of Maturation for Cancer Therapy. J. Pharm. Pharmacol. 52 (1), 75-82. doi:10.1211/0022357001773535

Happi, G. M., Kouam, S. F., Talontsi, F. M., Nkenfou, C. N., Longo, F., Zühlke, S., et al. (2015). A New Dimeric Naphtho- $\gamma$-Pyrone from an Endophytic Fungus Aspergillus niger AKRN Associated with the Roots of Entandrophragma Congoënse Collected in Cameroon. Z. Naturforschung Section B-a J. Chem. Sci. 70 (9), 625-630. doi:10.1515/znb-2015-0036

Hayden, N. J., Maude, R. B., and Proctor, F. J. (1994). Studies on the Biology of Black Mould (Aspergillus niger) on Temperate and Tropical Onions. 1. A Comparison of Sources of the Disease in Temperate and Tropical Field Crops. Plant Pathol. 43 (3), 562-569. doi:10.1111/j.1365-3059.1994.tb01591.x

He, Y., Wang, B., Chen, W., Cox, R. J., He, J., and Chen, F. (2018). Recent Advances in Reconstructing Microbial Secondary Metabolites Biosynthesis in Aspergillus Spp. Biotechnol. Adv. 36 (3), 739-783. doi:10.1016/j.biotechadv.2018.02.001

Hemphill, C. F. P., Sureechatchaiyan, P., Kassack, M. U., Orfali, R. S., Lin, W., Daletos, G., et al. (2017). OSMAC Approach Leads to New Fusarielin Metabolites from Fusarium Tricinctum. J. Antibiot. 70 (6), 726-732. doi:10.1038/ja.2017.21

Henrikson, J. C., Ellis, T. K., King, J. B., and Cichewicz, R. H. (2011). Reappraising the Structures and Distribution of Metabolites from Black Aspergilli Containing Uncommon 2-Benzyl-4h-Pyran-4-One and 2-Benzylpyridin-4(1h)-One Systems. J. Nat. Prod. 74 (9), 1959-1964. doi:10.1021/np200454z

Henrikson, J. C., Hoover, A. R., Joyner, P. M., and Cichewicz, R. H. (2009). A Chemical Epigenetics Approach for Engineering the in Situbiosynthesis of a Cryptic Natural Product from Aspergillus niger. Org. Biomol. Chem. 7 (3), 435-438. doi:10.1039/b819208a

Hiort, J., Maksimenka, K., Reichert, M., Perović-Ottstadt, S., Lin, W. H., Wray, V., et al. (2004). New Natural Products from the Sponge-Derived FungusAspergillus niger. J. Nat. Prod. 67 (9), 1532-1543. doi:10.1021/ np030551d

Holm, D. K., Petersen, L. M., Klitgaard, A., Knudsen, P. B., Jarczynska, Z. D., Nielsen, K. F., et al. (2014). Molecular and Chemical Characterization of the Biosynthesis of the 6-MSA-Derived Meroterpenoid Yanuthone D in Aspergillus niger. Chem. Biol. 21 (4), 519-529. doi:10.1016/ j.chembiol.2014.01.013

Hua, Y., Pan, R., Bai, X., Wei, B., Chen, J., Wang, H., et al. (2020). Aromatic Polyketides from a Symbiotic Strain Aspergillus fumigatus D and Characterization of Their Biosynthetic Gene D8.T287. Mar. Drugs 18 (6), 324. doi: $10.3390 / \mathrm{md} 18060324$

Hüttel, W., and Müller, M. (2007). Regio- and Stereoselective Intermolecular Oxidative Phenol Coupling in Kotanin Biosynthesis byAspergillus Niger. Chembiochem 8 (5), 521-529. doi:10.1002/cbic.200600434

Huttel, W., Nieger, M., and Muller, M. (2003). A Short and Efficient Total Synthesis of the Naturally Occurring Coumarins Siderin, Kotanin, Isokotanin A and Desertorin C. Synthesis-Stuttgart (12), 1803-1808. doi:10.1055/s-2003-41027

Jefferson, W. E., Jr. (1967). The Isolation and Characterization of Asperenone, a New Phenylpolyene from Aspergillus niger*. Biochemistry 6 (11), 3479-3484. doi:10.1021/bi00863a019

Jomori, T., Hara, Y., Sasaoka, M., Harada, K., Setiawan, A., Hirata, K., et al. (2020). Mycobacterium Smegmatis Alters the Production of Secondary Metabolites by marine-derived Aspergillus niger. J. Nat. Med. 74 (1), 76-82. doi:10.1007/ s11418-019-01345-0

Kaur, T., Singh, B., Kaur, A., and Kaur, S. (2015). Endophyte-mediated Interactions between Cauliflower, the Herbivore Spodoptera Litura, and the Ectoparasitoid Bracon Hebetor. Oecologia 179 (2), 487-494. doi:10.1007/s00442-015-3358-7

Kim, K.-W., Sugawara, F., Yoshida, S., Murofushi, N., Takahashi, N., and Curtis, R. W. (1993). Structure of Malformin B, a Phytotoxic Metabolite Produced byAspergillus niger. Biosci. Biotechnol. Biochem. 57 (5), 787-791. doi:10.1271/bbb.57.787

Kimura, Y., Sawada, A., Kuramata, M., Kusano, M., Fujioka, S., Kawano, T., et al. (2005). Brevicompanine C, Cyclo-( $d$-Ile-L-Trp), and Cyclo-(d-Leu-L-Trp), Plant Growth Regulators from Penicillium Brevi-Compactum. J. Nat. Prod. 68 (2), 237-239. doi:10.1021/np040178p

Kimura, Y., Tani, K., Kojima, A., Sotoma, G., Okada, K., and Shimada, A. (1996). Cyclo-(L-tryptophyl-L-phenylalanyl), a Plant Growth Regulator Produced by the Fungus Penicillium Sp. Phytochemistry 41 (3), 665-669. doi:10.1016/00319422(95)00693-1
Kodukula, K., Arcuri, M., Cutrone, J. Q., Hugill, R. M., Lowe, S. E., Pirnik, D. M., et al. (1995). BMS-192548, a Tetracyclic Binding Inhibitor of Neuropeptide Y Receptors, from Aspergillus niger WB2346. I. Taxonomy, Fermentation, Isolation and Biological Activity. J. Antibiot. 48 (10), 1055-1059. doi:10.7164/antibiotics.48.1055

Leutou, A. S., Yun, K., and Son, B. W. (2016). Induced Production of 6,9dibromoflavasperone, a New Radical Scavenging Naphthopyranone in the marine-mudflat-derived Fungus Aspergillus niger. Arch. Pharm. Res. 39 (6), 806-810. doi:10.1007/s12272-016-0764-2

Li, A., Pfelzer, N., Zuijderwijk, R., and Punt, P. (2012). Enhanced Itaconic Acid Production in Aspergillus niger Using Genetic Modification and Medium Optimization. BMC Biotechnol. 12. doi:10.1186/1472-6750-12-57

Li, C., Zhou, J., Du, G., Chen, J., Takahashi, S., and Liu, S. (2020). Developing Aspergillus niger as a Cell Factory for Food Enzyme Production. Biotechnol. Adv. 44, 107630. doi:10.1016/j.biotechadv.2020.107630

Li, D.-H., Han, T., Guan, L.-P., Bai, J., Zhao, N., Li, Z.-L., et al. (2016). New Naphthopyrones from marine-derived Fungus Aspergillus niger 2HL-M-8 and Their In Vitro Antiproliferative Activity. Nat. Product. Res. 30 (10), 1116-1122. doi:10.1080/14786419.2015.1043553

Li, M., Yu, R., Bai, X., Wang, H., and Zhang, H. (2020). Fusarium: a Treasure Trove of Bioactive Secondary Metabolites. Nat. Prod. Rep. 37, 1568-1588. doi:10.1039/ d0np00038h

Li, X.-B., Li, Y.-L., Zhou, J.-C., Yuan, H.-Q., Wang, X.-N., and Lou, H.-X. (2015). A New Diketopiperazine Heterodimer from an Endophytic Fungus Aspergillus niger. J. Asian Nat. Prod. Res. 17 (2), 182-187. doi:10.1080/ 10286020.2014 .959939

Li, X., Pan, L., Wang, B., and Pan, L. (2019). The Histone Deacetylases HosA and HdaA Affect the Phenotype and Transcriptomic and Metabolic Profiles of Aspergillus niger. Toxins 11 (9), 520. doi:10.3390/toxins11090520

Li, Y., Chooi, Y.-H., Sheng, Y., Valentine, J. S., and Tang, Y. (2011). Comparative Characterization of Fungal Anthracenone and Naphthacenedione Biosynthetic Pathways Reveals an a-Hydroxylation-Dependent Claisen-like Cyclization Catalyzed by a Dimanganese Thioesterase. J. Am. Chem. Soc. 133 (39), 15773-15785. doi:10.1021/ja206906d

Liu, D., Li, X.-M., Li, C.-S., and Wang, B.-G. (2013). Nigerasterols A and B, Antiproliferative Sterols from the Mangrove-Derived Endophytic FungusAspergillus nigerMA-132. Hca 96 (6), 1055-1061. doi:10.1002/ hlca.201200332

Liu, D., Li, X.-M., Meng, L., Li, C.-S., Gao, S.-S., Shang, Z., et al. (2011). Nigerapyrones A-H, $\alpha$-Pyrone Derivatives from the Marine MangroveDerived Endophytic FungusAspergillus nigerMA-132. J. Nat. Prod. 74 (8), 1787-1791. doi:10.1021/np200381u

Liu, Y., Nan, L., Liu, J., Yan, H., Zhang, D., and Han, X. (2016). Isolation and Identification of Resveratrol-Producing Endophytes from Wine Grape Cabernet Sauvignon. Springerplus 5. doi:10.1186/s40064-016-2571-0

Lu, H., Cao, W., Ouyang, L., Xia, J., Huang, M., Chu, J., et al. (2017). Comprehensive Reconstruction and In Silico Analysis ofAspergillus Nigergenome-Scale Metabolic Network Model that Accounts for 1210 ORFs. Biotechnol. Bioeng. 114 (3), 685-695. doi:10.1002/bit.26195

Lu, S., Tian, J., Sun, W., Meng, J., Wang, X., Fu, X., et al. (2014). Bis-naphtho$\gamma$-pyrones from Fungi and Their Bioactivities. Molecules 19 (6), 7169-7188. doi:10.3390/molecules 19067169

Manganyi, M. C., Regnier, T., Kumar, A., Bezuidenhout, C. C., and Ateba, C. N. (2018). Biodiversity and Antibacterial Screening of Endophytic Fungi Isolated from Pelargonium Sidoides. South Afr. J. Bot. 116, 192-199. doi:10.1016/ j.sajb.2018.03.016

Miyake, Y., Ito, C., Itoigawa, M., and Osawa, T. (2007). Isolation of the Antioxidant Pyranonigrin-A from rice Mold Starters Used in the Manufacturing Process of Fermented Foods. Biosci. Biotechnol. Biochem. 71 (10), 2515-2521. doi:10.1271/ bbb.70310

Nielsen, K. F., Mogensen, J. M., Johansen, M., Larsen, T. O., and Frisvad, J. C. (2009). Review of Secondary Metabolites and Mycotoxins from the Aspergillus niger Group. Anal. Bioanal. Chem. 395 (5), 1225-1242. doi:10.1007/s00216009-3081-5

Nødvig, C. S., Hoof, J. B., Kogle, M. E., Jarczynska, Z. D., Lehmbeck, J., Klitgaard, D. K., et al. (2018). Efficient Oligo Nucleotide Mediated CRISPR-Cas9 Gene Editing in Aspergilli. Fungal Genet. Biol. 115, 78-89. doi:10.1016/ j.fgb.2018.01.004 
Nødvig, C. S., Nielsen, J. B., Kogle, M. E., and Mortensen, U. H. (2015). A CRISPRCas9 System for Genetic Engineering of Filamentous Fungi. PLoS One 10 (7), e0133085. doi:10.1371/journal.pone.0133085

Obermaier, S., and Müller, M. (2019). Biaryl-Forming Enzymes from Aspergilli Exhibit Substrate-dependent Stereoselectivity. Biochemistry 58 (22), 2589-2593. doi:10.1021/acs.biochem.9b00291

Ovenden, S. P. B., Sberna, G., Tait, R. M., Wildman, H. G., Patel, R., Li, B., et al. (2004). A Diketopiperazine Dimer from a Marine-Derived Isolate ofAspergillusniger. J. Nat. Prod. 67 (12), 2093-2095. doi:10.1021/np0497494

Özer, N., and Köycü, N. D. (2006). The Ability of Plant Compost Leachates to Control Black Mold (Aspergillus niger) and to Induce the Accumulation of Antifungal Compounds in Onion Following Seed Treatment. Biocontrol 51 (2), 229-243. doi:10.1007/s10526-005-1035-1

Padhi, S., Masi, M., Panda, S. K., Luyten, W., Cimmino, A., Tayung, K., et al. (2020). Antimicrobial Secondary Metabolites of an Endolichenic Aspergillus niger Isolated from Lichen Thallus of Parmotrema Ravum. Nat. Product. Res. 34 (18), 2573-2580. doi:10.1080/14786419.2018.1544982

Pan, R., Bai, X., Chen, J., Zhang, H., and Wang, H. (2019). Exploring Structural Diversity of Microbe Secondary Metabolites Using OSMAC Strategy: a Literature Review. Front. Microbiol. 10. doi:10.3389/fmicb.2019.00294

Pel, H. J., de Winde, J. H., Archer, D. B., Dyer, P. S., Hofmann, G., Schaap, P. J., et al. (2007). Genome Sequencing and Analysis of the Versatile Cell Factory Aspergillus niger CBS 513.88. Nat. Biotechnol. 25 (2), 221-231. doi:10.1038/ nbt1282

Perrone, G., Stea, G., Epifani, F., Varga, J., Frisvad, J. C., and Samson, R. A. (2011). Aspergillus niger Contains the Cryptic Phylogenetic Species A. Awamori. Fungal Biol. 115 (11), 1138-1150. doi:10.1016/j.funbio.2011.07.008

Rao, K. C. S., Divakar, S., Babu, K. N., Rao, A. G. A., Karanth, N. G., and Sattur, A. P. (2002). Nigerloxin, a Novel Inhibitor of Aldose Reductase and Lipoxygenase with Free Radical Scavenging Activity from Aspergillus niger CFR-W-105. J. Antibiot. 55 (9), 789-793. doi:10.7164/antibiotics.55.789

Reber, K. P., and Burdge, H. E. (2018). Total Synthesis of Pyrophen and Campyrones A-C. J. Nat. Prod. 81 (2), 292-297. doi:10.1021/ acs.jnatprod.7b00720

Riko, R., Nakamura, H., and Shindo, K. (2014). Studies on Pyranonigrins-Isolation of Pyranonigrin E and Biosynthetic Studies on Pyranonigrin A. J. Antibiot. 67 (2), 179-181. doi:10.1038/ja.2013.91

Saeed, S., Aslam, S., Mehmood, T., Naseer, R., Nawaz, S., Mujahid, H., et al. (2020). Production of Gallic Acid under Solid-State Fermentation by Utilizing Waste from Food Processing Industries. Waste Biomass Valor. 12 (1), 155-163. doi:10.1007/s12649-020-00980-Z

Sakurai, M., Kohno, J., Yamamoto, K., Okuda, T., Nishio, M., Kawano, K., et al. (2002). TMC-256A1 and C1, New Inhibitors of IL-4 Signal Transduction Produced by Aspergillus niger Var niger TC 1629. J. Antibiot. 55 (8), 685-692. doi:10.7164/antibiotics.55.685

Sanchez, J. F., Somoza, A. D., Keller, N. P., and Wang, C. C. C. (2012). Advances in Aspergillus Secondary Metabolite Research in the post-genomic Era. Nat. Prod. Rep. 29 (3), 351-371. doi:10.1039/c2np00084a

Santhakumaran, I., Kesavan, S. S., and Arumugam, G. (2019). Asperyellone Pretreatment Protects HaCaT Cells from UVB Irradiation Induced Oxidative Damages: Assessment under In Vitro and In Vivo Conditions and at Molecular Level. J. Cel Biochem 120 (6), 10715-10725. doi:10.1002/jcb.28363

Shen, L., Ye, Y.-H., Wang, X.-T., Zhu, H.-L., Xu, C., Song, Y.-C., et al. (2006). Structure and Total Synthesis of Aspernigerin: A Novel Cytotoxic Endophyte Metabolite. Chem. Eur. J. 12 (16), 4393-4396. doi:10.1002/chem.200501423

Shreelalitha, S. J., and Sridhar, K. R. (2015). Endophytic Fungi of Wild Legume Sesbania Bispinosa in Coastal Sand Dunes and Mangroves of the Southwest Coast of India. J. For. Res. 26 (4), 1003-1011. doi:10.1007/s11676-015-0103-3

Shu, Y.-Z., Cutrone, J. Q., Klohr, S. E., and Huang, S. (1995). BMS-192548, a Tetracyclic Binding Inhibitor of Neuropeptide Y Receptors, from Aspergillus niger WB2346. II. Physico-Chemical Properties and Structural Characterization. J. Antibiot. 48 (10), 1060-1065. doi:10.7164/antibiotics.48.1060

Singh, S. M., Yadav, L. S., Singh, S. K., Singh, P., Singh, P. N., and Ravindra, R. (2011). Phosphate Solubilizing Ability of Two Arctic Aspergillus niger Strains. Polar Res. 30. doi:10.3402/polar.v30i0.7283

Soltani, J., and Moghaddam, M. S. H. (2014). Diverse and Bioactive Endophytic Aspergilli Inhabit Cupressaceae Plant Family. Arch. Microbiol. 196 (9), 635-644. doi:10.1007/s00203-014-0997-8
Song, Y. C., Li, H., Ye, Y. H., Shan, C. Y., Yang, Y. M., and Tan, R. X. (2004). Endophytic Naphthopyrone Metabolites Are Co-inhibitors of Xanthine Oxidase, SW1116 Cell and Some Microbial Growths. FEMS Microbiol. Lett. 241 (1), 67-72. doi:10.1016/j.femsle.2004.10.005

Sørensen, L. M., Lametsch, R., Andersen, M. R., Nielsen, P. V., and Frisvad, J. C. (2009). Proteome Analysis of Aspergillus niger: Lactate Added in StarchContaining Medium Can Increase Production of the Mycotoxin Fumonisin B2 by Modifying Acetyl-CoA Metabolism. BMC Microbiol. 9, 255. doi:10.1186/ 1471-2180-9-255

Suda, S., and Curtis, R. W. (1966). Antibiotic Properties of Malformin. Appl. Microbiol. 14 (3), 475-476. doi:10.1128/aem.14.3.475-476.1966

Sun, J., Lu, X., Rinas, U., and Zeng, A. (2007). Metabolic Peculiarities of Aspergillus niger Disclosed by Comparative Metabolic Genomics. Genome Biol. 8 (9), R182. doi:10.1186/gb-2007-8-9-r182

Takano, D., Nagamitsu, T., Ui, H., Shiomi, K., Yamaguchi, Y., Masuma, R., et al. (2001). Absolute Configuration of Nafuredin, a New Specific NADH-Fumarate Reductase Inhibitor. Tetrahedron Lett. 42 (16), 3017-3020. doi:10.1016/s00404039(01)00355-0

Talontsi, F. M., Tatong, M. D. K., Dittrich, B., Douanla-Meli, C., and Laatsch, H. (2013). Structures and Absolute Configuration of Three Alpha-Pyrones from an Endophytic Fungus Aspergillus niger. Tetrahedron 69 (34), 7147-7151. doi:10.1016/j.tet.2013.05.098

Tanaka, H., Pie-Lang, W., and Namiki, M. (1972). Structure of Aurasperone C. Agric. Biol. Chem. 36 (13), 2511-2517. doi:10.1080/00021369.1972.10860562

Tanaka, H., Wang, P.-L., Yamada Late, O., and Tamura, T. (1966). Yellow Pigments ofAspergillus nigerandAsp. Awamori. Agric. Biol. Chem. 30 (2), 107-113. doi:10.1080/00021369.1966.10858561

Toghueo, R. M. K., Sahal, D., Zabalgogeazcoa, Í., Baker, B., and Boyom, F. F. (2018). Conditioned media and Organic Elicitors Underpin the Production of Potent Antiplasmodial Metabolites by Endophytic Fungi from Cameroonian Medicinal Plants. Parasitol. Res. 117 (8), 2473-2485. doi:10.1007/s00436-018-5936-1

Uchoa, P. K. S., Pimenta, A. T. A., Braz-Filho, R., de Oliveira, M. d. C. F., Saraiva, N. N., Rodrigues, B. S. F., et al. (2017). New Cytotoxic Furan from the marine Sediment-Derived Fungi Aspergillus niger. Nat. Product. Res. 31 (22), 2599-2603. doi:10.1080/14786419.2017.1283499

Ui, H., Shiomi, K., Yamaguchi, Y., Masuma, R., Nagamitsu, T., Takano, D., et al. (2001). Nafuredin, a Novel Inhibitor of NADH-Fumarate Reductase, Produced by Aspergillus niger FT-0554. J. Antibiot. 54 (3), 234-238. doi:10.7164/antibiotics.54.234

Varoglu, M., Corbett, T. H., Valeriote, F. A., and Crews, P. (1997). Asperazine, a Selective Cytotoxic Alkaloid from a Sponge-Derived Culture ofAspergillus niger. J. Org. Chem. 62 (21), 7078-7079. doi:10.1021/jo970568z

Varoglu, M., and Crews, P. (2000). Biosynthetically Diverse Compounds from a Saltwater Culture of Sponge-DerivedAspergillus niger. J. Nat. Prod. 63 (1), 41-43. doi:10.1021/np9902892

Wang, B., Li, X., Yu, D., Chen, X., Tabudravu, J., Deng, H., et al. (2018). Deletion of the Epigenetic Regulator GcnE in Aspergillus niger FGSC A1279 Activates the Production of Multiple Polyketide Metabolites. Microbiol. Res. 217, 101-107. doi:10.1016/j.micres.2018.10.004

Wang, J., Jiang, Z., Lam, W., Gullen, E. A., Yu, Z., Wei, Y., et al. (2015). Study of Malformin C, a Fungal Source Cyclic Pentapeptide, as an Anti-cancer Drug. PLoS One 10 (11), e0140069. doi:10.1371/journal.pone.0140069

Wang, L.-X., Ren, L.-L., Liu, X.-B., Shi, J., Wang, J.-Z., and Luo, Y.-Q. (2019). Effects of Endophytic Fungi in Mongolian pine on the Selection Behavior of Woodwasp (Sirex noctilio) and the Growth of its Fungal Symbiont. Pest Manag. Sci. 75 (2), 492-505. doi:10.1002/ps.5146

Wei, Q., Bai, J., Yan, D., Bao, X., Li, W., Liu, B., et al. (2021). Genome Mining Combined Metabolic Shunting and OSMAC Strategy of an Endophytic Fungus Leads to the Production of Diverse Natural Products. Acta Pharmaceutica Sinica $B 11$ (2), 572-587. doi:10.1016/j.apsb.2020.07.020

Xie, H., Zhuang, X., Bai, Z., Qi, H., and Zhang, H. (2006). Isolation of Levoglucosan-Assimilating Microorganisms from Soil and an Investigation of Their Levoglucosan Kinases. World J. Microbiol. Biotechnol. 22 (9), 887-892. doi:10.1007/s11274-006-9133-5

Xu, Y., Shan, L., Zhou, Y., Xie, Z., Ball, A. S., Cao, W., et al. (2019). Development of a Cre-loxP-Based Genetic System in Aspergillus niger ATCC1015 and its Application to Construction of Efficient Organic Acid-Producing Cell Factories. Appl. Microbiol. Biotechnol. 103 (19), 8105-8114. doi:10.1007/ s00253-019-10054-3 
Yamamoto, T., Tsunematsu, Y., Noguchi, H., Hotta, K., and Watanabe, K. (2015). Elucidation of Pyranonigrin Biosynthetic Pathway Reveals a Mode of Tetramic Acid, Fused $\gamma$-Pyrone, and Exo-Methylene Formation. Org. Lett. 17 (20), 4992-4995. doi:10.1021/acs.orglett.5b02435

Yang, X.-L., Awakawa, T., Wakimoto, T., and Abe, I. (2014). Three Acyltetronic Acid Derivatives: Noncanonical Cryptic Polyketides fromAspergillus nigerIdentified by Genome Mining. Chembiochem 15 (11), 1578-1583. doi:10.1002/cbic.201402172

Zabala, A. O., Xu, W., Chooi, Y.-H., and Tang, Y. (2012). Characterization of a Silent Azaphilone Gene Cluster from Aspergillus niger ATCC 1015 Reveals a Hydroxylation-Mediated Pyran-Ring Formation. Chem. Biol. 19 (8), 1049-1059. doi:10.1016/j.chembiol.2012.07.004

Zhang, Y., Li, X.-M., Feng, Y., and Wang, B.-G. (2010). Phenethyl-a-pyrone Derivatives and Cyclodipeptides from a marine Algous Endophytic Fungus Aspergillus niger EN-13. Nat. Product. Res. 24 (11), 1036-1043. doi:10.1080/ 14786410902940875

Zhang, Y., Li, X.-M., Proksch, P., and Wang, B.-G. (2007a). Ergosterimide, a New Natural Diels-Alder Adduct of a Steroid and Maleimide in the Fungus Aspergillus niger. Steroids 72 (9-10), 723-727. doi:10.1016/j.steroids.2007.05.009

Zhang, Y., Li, X.-M., and Wang, B.-G. (2007b). Nigerasperones A C, New Monomeric and Dimeric Naphtho- $\gamma$-Pyrones from a Marine Alga-Derived Endophytic Fungus Aspergillus niger EN-13. J. Antibiot. 60 (3), 204-210. doi:10.1038/ja.2007.24

Zhang, Y., Zhang, X., Yu, Q., Yuan, Z., and Chen, X. (2019). Mutant Breeding of Furfural Tolerant Aspergillus terreus for Itaconic Acid Production. $j$ biobased mat bioenergy 13 (6), 799-805. doi:10.1166/jbmb.2019.1909
Zhou, X., Fang, W., Tan, S., Lin, X., Xun, T., Yang, B., et al. (2016). Aspernigrins with Anti-HIV-1 Activities from the marine-derived Fungus Aspergillus niger SCSIO Jcsw6F30. Bioorg. Med. Chem. Lett. 26 (2), 361-365. doi:10.1016/ j.bmcl.2015.12.005

Zou, S.-P., Zhong, W., Xia, C.-J., Gu, Y.-N., Niu, K., Zheng, Y.-G., et al. (2015). Mutagenesis Breeding of High Echinocandin B Producing Strain and Further Titer Improvement with Culture Medium Optimization. Bioproc. Biosyst Eng 38 (10), 1845-1854. doi:10.1007/s00449-015-1425-4

Conflict of Interest: The authors declare that the research was conducted in the absence of any commercial or financial relationships that could be construed as a potential conflict of interest.

Publisher's Note: All claims expressed in this article are solely those of the authors and do not necessarily represent those of their affiliated organizations, or those of the publisher, the editors and the reviewers. Any product that may be evaluated in this article, or claim that may be made by its manufacturer, is not guaranteed or endorsed by the publisher.

Copyright (C) 2021 Yu, Liu, Wang, Wang and Zhang. This is an open-access article distributed under the terms of the Creative Commons Attribution License (CC BY). The use, distribution or reproduction in other forums is permitted, provided the original author(s) and the copyright owner(s) are credited and that the original publication in this journal is cited, in accordance with accepted academic practice. No use, distribution or reproduction is permitted which does not comply with these terms. 